\title{
Surface Modification of Carbon Nanotube Networked Films with Au Nanoclusters for Enhanced $\mathrm{NO}_{2}$ Gas Sensing Applications
}

\author{
M. Penza, ${ }^{1}$ R. Rossi, ${ }^{1}$ M. Alvisi, ${ }^{1}$ G. Cassano, ${ }^{1}$ M. A. Signore, ${ }^{1}$ E. Serra, ${ }^{2}$ and R. Giorgi ${ }^{2}$ \\ ${ }^{1}$ Department of Physical Technologies and New Materials, ENEA, C.R. Brindisi, P.O. Box 51 Br-4, 72100 Brindisi, Italy \\ ${ }^{2}$ Department of Physical Technologies and New Materials, ENEA, C.R. Casaccia, P.O. Box 2400, 00100 Rome, Italy
}

Correspondence should be addressed to M. Penza, michele.penza@brindisi.enea.it

Received 30 May 2008; Accepted 22 September 2008

Recommended by Kourosh Kalantar-Zadeh

Multiwalled carbon nanotube (MWCNT) films have been deposited by using plasma-enhanced chemical vapor deposition (PECVD) system onto alumina substrates, provided with $6 \mathrm{~nm}$ thick cobalt $(\mathrm{Co})$ growth catalyst for remarkably improved $\mathrm{NO}_{2}$ gas sensing, at working temperature in the range of $100-250^{\circ} \mathrm{C}$. Functionalization of the MWCNTs with nanoclusters of gold $\mathrm{Au}$ ) sputtering has been performed to modify the surface of carbon nanotube networked films for enhanced and specific $\mathrm{NO}_{2}$ gas detection up to sub-ppm level. It is demonstrated that the $\mathrm{NO}_{2}$ gas sensitivity of the MWCNT-based sensors depends on Au-loading used as surface-catalyst. The gas response of MWCNT-based chemiresistor is attributed to p-type conductivity in the Au-modified semiconducting MWCNTs with a very good short-term repeatability and faster recovery. The sensor temperature of maximum $\mathrm{NO}_{2}$ sensitivity of the Au-functionalized MWCNTs is found to decrease with increasing Au-loading on their surface, and continuous gas monitoring at ppb level of $\mathrm{NO}_{2}$ is effectively performed with Au-modified MWCNT chemiresistors.

Copyright (c) 2008 M. Penza et al. This is an open access article distributed under the Creative Commons Attribution License, which permits unrestricted use, distribution, and reproduction in any medium, provided the original work is properly cited.

\section{INTRODUCTION}

Carbon nanotubes [1] (CNTs) are quasi-one-dimensional nanostructures that exhibit very attractive structural, electrical, optical, and mechanical properties for emerging nanotechnology devices [2]. In particular, the CNTs are considered promising nanomaterials for gas sensing due to their large surface-to-volume ratio and hollow structure. CNTs have been used for detecting small concentrations of gases [3-7] with high sensitivity upon ambient conditions with different types and geometries of transducers $[6,8-$ 13]. The adsorption of electron-withdrawing (e.g., $\mathrm{NO}_{2}$ ) or electron-donating (e.g., $\mathrm{NH}_{3}$ ) molecules onto the surface of CNTs causes a charge transfer between CNTs and the gas molecules with a typical p-type electrical behavior of semiconducting carbon nanotubes. Hole carriers are increased in the CNTs when exposed to $\mathrm{NO}_{2}$ gas, causing an increase in their conductance. The interaction with the $\mathrm{NH}_{3}$ gas produced an opposite effect.

The need for air-quality monitoring demands the development of highly sensitive sensors that are selective for the detection of individual pollutant gases, especially $\mathrm{NO}_{2}$ gas which is a very toxic air-pollutant to be detected at subppm level with high sensitivity and selectivity. Gas sensors based on CNTs are commonly cross-sensitive to many target gases with low specificity. Different strategies involving their surface modifications have been used to enhance sensitivity and/or selectivity toward various gases: wrapped polymer coatings [14], molecular engineering of purified CNT-based nanocomposites [15], polymer functionalization of carbon nanotubes for fabricating nanocomposite [16], surfacefunctionalizations with specific functional groups [17], and chemical and physical modifications with metal nanoclusters [18]. The limitations of the low selectivity and slow recovery at room temperature of the CNT chemiresistors have been investigated with successful attempts by means of functionalizations with metal catalyst nanoclusters and operations at sensor temperatures above room temperature up to $200-300^{\circ} \mathrm{C}$. Recently, our work [19] demonstrated that nanoclusters of gold $(\mathrm{Au})$ and platinum $(\mathrm{Pt})$ enhance the gas sensitivity of CNT-based chemiresistors for $\mathrm{NO}_{2}$ and $\mathrm{NH}_{3}$ gas, respectively, with a working temperature in the range of 
$100-250^{\circ} \mathrm{C}$ achieving faster recovery than room-temperature operation.

In this study, we investigate the effects of the tailored loading of Au-nanoclusters, which were deposited onto the surface of the modified CNTs, on the electrical properties of the CNTs gas sensors for selective $\mathrm{NO}_{2}$ gas environmental monitoring, at sensor temperature in the range of $100-$ $250^{\circ} \mathrm{C}$.

\section{EXPERIMENTAL}

\subsection{Growth of carbon nanotubes and sensor fabrication}

Multiwalled carbon nanotube (MWCNT) layers were prepared by a radiofrequency plasma-enhanced chemical vapor deposition (RF-PECVD) system, at a reasonably low growthtemperature of $450^{\circ} \mathrm{C}$, onto low-cost alumina substrates ( $10 \mathrm{~mm}$ width $\times 10 \mathrm{~mm}$ length $\times 0.6 \mathrm{~mm}$ thickness $)$. A schematic view of the fabricated chemiresistor utilized is shown in Figure 1. A film of cobalt (Co) nanoclusters with a nominal thickness of $6 \mathrm{~nm}$ was sputtering deposited at $10^{-1}$ mbar onto room-temperature substrates for MWCNTs growth. The catalysed-substrates were heated to $450^{\circ} \mathrm{C}$ with a heating rate of $10^{\circ} \mathrm{C} / \mathrm{min}$ in $\mathrm{H}_{2}$ atmosphere, with an $\mathrm{H}_{2}$ flow of $100 \mathrm{sccm}$ at a total pressure of 1.5 Torr. After the process temperature of $450^{\circ} \mathrm{C}$ is reached, an $\mathrm{H}_{2}$ plasma pretreatment was performed at an $\mathrm{rf}$ power $(13.56 \mathrm{MHz})$ of 100 Watts for 10 minutes to obtain the metallic nanoclusters necessary for the nanotubes growth. Then, acetylene $\left(\mathrm{C}_{2} \mathrm{H}_{2}\right)$, as carbon precursor, was introduced into the chamber. The gas flow rate ratio between $\mathrm{C}_{2} \mathrm{H}_{2}$ and $\mathrm{H}_{2}$ was kept constant at 20/80 sccm, respectively. The MWCNTs PECVDdeposition was performed with constant rf power, pressure, and temperature of 100 Watts, 1.5 Torr, and $450^{\circ} \mathrm{C}$, respectively, for 30 minutes by depositing a carbon nanotube networked film that was estimated as about $250-300 \mathrm{~nm}$ thick. Modification of the MWCNTs involved DC-sputtering of tailored loading of $\mathrm{Au}$ nanoclusters with a nominal thickness of 2.5, 5, and $10 \mathrm{~nm}$ over the entire substrate coated by MWCNTs. Two metal strips ( $2 \mathrm{~mm}$ width $\times 10 \mathrm{~mm}$ length) of $\mathrm{Cr}(20 \mathrm{~nm}) / \mathrm{Au}(350 \mathrm{~nm})$ were vacuum evaporated onto MWCNT films for electrical contacts in the two-pole geometry. The electrical resistance, at room temperature, of unfunctionalized and Au-modified MWCNTs with increasing loading was measured as $9.2(0 \mathrm{~nm} \mathrm{Au}), 8.1(2.5 \mathrm{~nm}$ $\mathrm{Au}), 7.2(5 \mathrm{~nm} \mathrm{Au})$, and $6.8(10 \mathrm{~nm} \mathrm{Au}) \mathrm{k} \Omega$, respectively. Thus, the surface modification of MWCNTs with increasing loading of Au-catalyst is found to decrease the resistance of the carbon nanotube networked films, as expected. Before gas sensing exposure, the unfunctionalized MWCNTs and Au-modified MWCNTs were thermally annealed at $300^{\circ} \mathrm{C}$ upon dry air flow for 2 hours to purify the MWCNTs removing amorphous carbon and to stabilize the sensing properties of catalyst nanoclusters improving their adhesion onto MWCNTs.

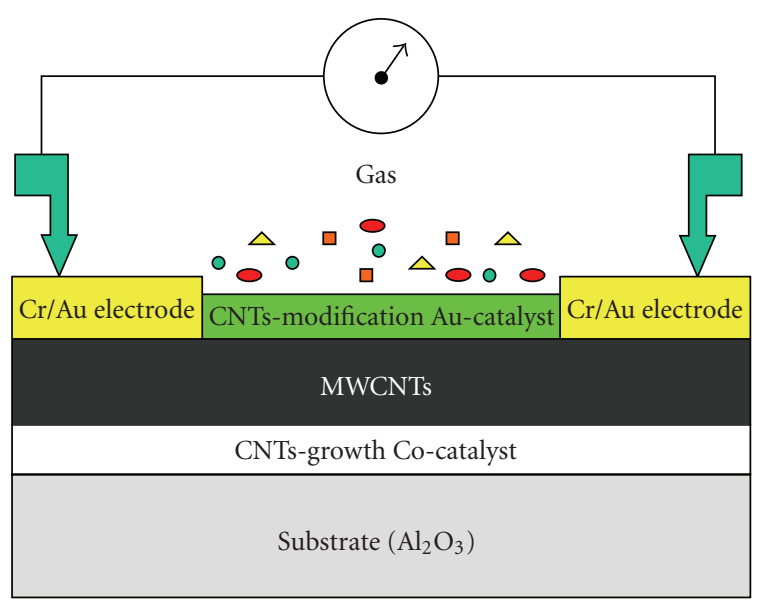

Figure 1: Cross-sectional view of the two-pole chemiresistor based on Au-modified carbon nanotubes, grown with Co-catalyst by means of RF-PECVD technology.

\subsection{Measurements setup}

The experimental setup used for gas sensing measurements of the multiple chemiresistors upon multiplexed readout and controlled gas flow system is shown in Figure 2. The sofabricated MWCNT sensors have been located in a test cell (500 mL volume) for gas exposure measurements. The cell case is able to host up to four chemiresitive sensors. The sensors were at thermal contact with a hot-plate, powered by a dc power supply (Agilent, 6644A) for controlling the desired working temperature. Dry air was used as reference gas and diluting gas to air-conditioning the sensors. The gas flow rate was controlled by different mass flowmeters (MFC) with various full scale. These digital MFCs (MKS $1179 \mathrm{~A}$ ) were regulated and driven by a controller-unit (MKS, GGK DMFC-5), equipped with a multiplexing/conversion system communicating with a desktop-host via standard RS485/RS-232 serial bus. The total flow rate per exposure was kept constant at $1500 \mathrm{~mL} / \mathrm{min}$. The gas sensing experiments have been performed by measuring the electrical conductance of MWCNT thin films in the two-pole format upon controlled ambient of $\mathrm{NO}_{2}$ oxidizing gas and $\mathrm{NH}_{3}$ reducing gas in the range of $100 \mathrm{ppb}-10 \mathrm{ppm}$ and $5-1000 \mathrm{ppm}$, respectively, at sensor temperature ranging from 100 to $250^{\circ} \mathrm{C}$. The sensor temperature was measured by a J-type thermocouple, whose output dc voltage was measured by a multimeter (Agilent, 34401A).

The dc electrical conductance of the MWCNT sensors has been measured by the volt-amperometric technique in the two-pole format by a multimeter (Agilent, 34401A). The sensors were scanned by a switch system (Keithley, 7001) equipped by a low-current scanner card (Keithley, 7158) with a multiplexed read-out. All acquired data were stored in a PC-based workstation, interfaced with instrumentation by USB-GPIB card (Agilent, 82357A), in software ambient compiled in Agilent-VEE. 


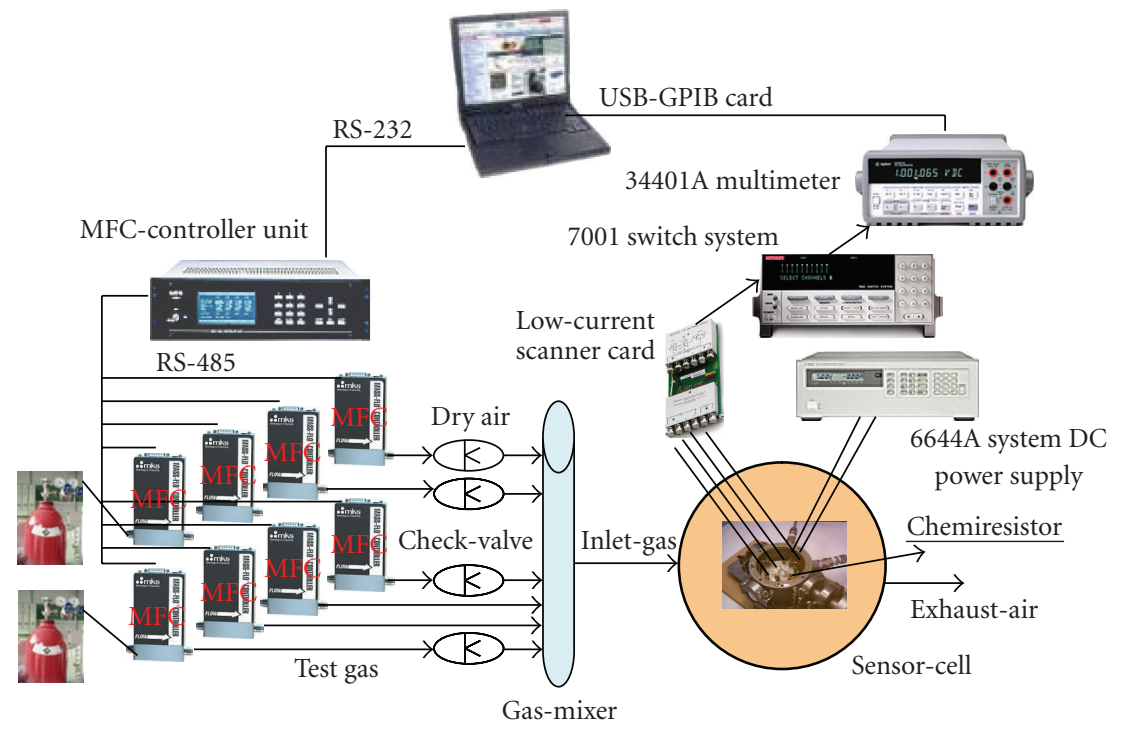

FIGURE 2: Experimental setup for gas sensing measurements of the multiple chemiresistors in multiplexed read-out.

\section{RESULTS AND DISCUSSION}

Figure 3 displays field emission gun-scanning electron microscopy (FEG-SEM) images of unfunctionalized MWCNT films and surface-modified with the increasing of Au-loading of 2.5, 5, and $10 \mathrm{~nm}$. The nanostructures show a pronounced tubular structure forming a tangled net of bundled nanotubular chains densely distributed in mats. Some amount of amorphous carbon is still present in the samples, even after the purification procedure mentioned. A complete removal of amorphous carbon should require higher temperature and/or longer annealing time although structural damage should be avoided in the nanotube carbon-based material. However, the average diameter of the MWCNTs seems to be varied in the range of $10-30 \mathrm{~nm}$. The Au particles partially decorating MWCNT sidewalls form isolated nanoclusters with increasing size in the range of 5-15 nm, 5-30 nm, and 5-60 nm, respectively, with the increasing Au-loading deposited onto CNTs due to migration and coalescence of the $\mathrm{Au}$ atoms induced by the temperature. The rational modification of the CNTs surface with $\mathrm{Au}$ nanoclusters enables nanotubes with tunable surface properties for the fabrication of selective gas sensors. The catalytic covering of nanotubes strongly affects their properties of gas adsorption, hence, the tailoring of gas sensitivity.

Figure 4 reports the time response of the MWCNT chemiresistors, unfunctionalized and surface-modified with different nanoclustered Au-loading of 2.5, 5, and $10 \mathrm{~nm}$, exposed to 10-minute pulses of decreasing spot concentrations of $\mathrm{NO}_{2}$ gas in the low range from 4 to $0.5 \mathrm{ppm}$. The working sensor temperature was $200^{\circ} \mathrm{C}$ with the relative humidity in test cell of about $20 \%$. The electrical resistance of Au-loaded and unloaded MWCNT devices decreases rapidly when exposed to $\mathrm{NO}_{2}$ gas, thus the $p$-type characteristic is maintained also after functionalization of the MWCNTs with
Au nanoclusters. The p-type character of the semiconducting CNTs in the unfunctionalized format has been found by several theoretical studies and experimental investigations reported in $[3,4,6,7,19]$. Also, the functionalizing material of the CNTs could change from $p$-type to $n$ type the electrical behavior of the functionalized CNTs, as in the case of polyethyleneimine functional layer [7]. At this operating temperature of $200^{\circ} \mathrm{C}$, all MWCNT sensors show a fast recovery upon dry air of the baseline. The MWCNTs functionalized with various Au-loadings exhibit a faster recovery with respect to unloaded MWCNTs. A first rapid recovery step is followed by a slower second step in the functionalized MWCNT-based sensors. This could be attributed to the rapid desorption of the $\mathrm{NO}_{2}$ molecules in the first recovery step, and a slower desorption of $\mathrm{NO}_{3}$ molecules, formed by dissociation of two $\mathrm{NO}_{2}$ molecules onto CNTs surface [20]. The slower desorption of $\mathrm{NO}_{3}$ molecules from CNTs is explained by their higher binding energy, ranging from -1.0 to $-1.2 \mathrm{eV}$, with respect to $\mathrm{NO}_{2}$ molecules with lower binding energy, ranging from -0.34 to $-0.79 \mathrm{eV}$. Thus, the $\mathrm{NO}_{3}$ molecules are the most likely longlived species on CNTs [20]. Different strategies for speeding the recovery phenomena are the degassing by heating of the sensor at a temperature above operating temperature [21], the increased flux of the carrier gas during the recovery step [21], and ultraviolet illumination during the photoinduced recovery [22].

In our experiments, the sensor response has been calculated as the percentage relative resistance change $\Delta R / R_{i}$ $(\%)=\left[\left(R_{i}-R_{f}\right) / R_{i}\right](\%)$, where $R_{i}$ and $R_{f}$ are the electrical resistance steady-state values of the MWCNT films upon exposure to dry air and test gas, respectively. The inset of Figure 4(a) shows the calibration curves of the MWCNT sensors, unmodified and functionalized with various $\mathrm{Au}-$ loading nanoclusters, exposed to a wide range of $\mathrm{NO}_{2}$ low concentrations, at sensor temperature of $200^{\circ} \mathrm{C}$. The 


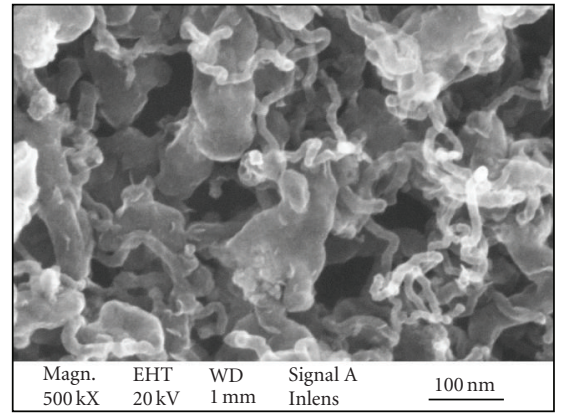

(a)

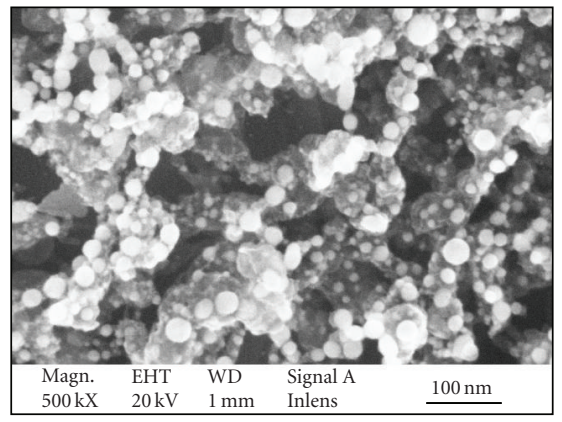

(c)

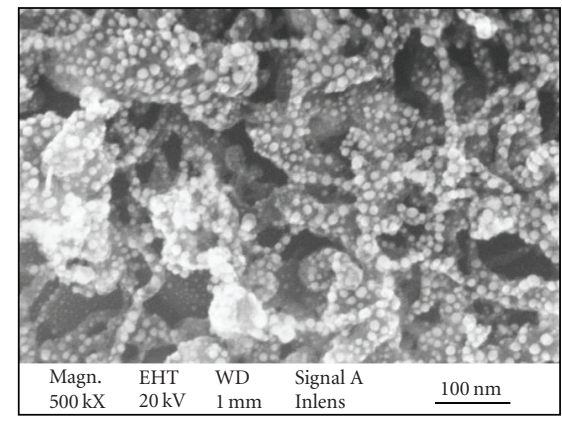

(b)

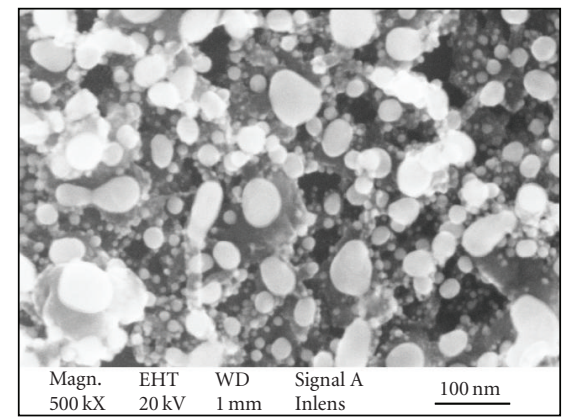

(d)

FIgUre 3: FEG-SEM image at high magnification of RF-PECVD MWCNT films, using a $6 \mathrm{~nm}$ thick Co growth catalyst onto alumina substrate, (a) without Au-nanoclusters and with (b) $2.5 \mathrm{~nm}$ Au loading, (c) $5 \mathrm{~nm} \mathrm{Au} \mathrm{loading,} \mathrm{(d)} 10 \mathrm{~nm}$ Au loading.

comparison of $\mathrm{NO}_{2}$ gas sensitivity demonstrates that all $\mathrm{Au}-$ modified MWCNTs have higher sensitivity than unfunctionalized MWCNT sensor up to two times more; and the highest sensitivity to $\mathrm{NO}_{2}$ has been achieved by the MWCNTs with Au-loading of $5 \mathrm{~nm}$. This enhanced $\mathrm{NO}_{2}$ gas sensitivity of Au-loaded MWCNT sensors mainly depends on the catalytic activity of the $\mathrm{Au}$ nanoclusters improving their sensing performance. The chemical activity of Au may change with nanocluster size $[23,24]$ : the fraction of low-coordinated $\mathrm{Au}$ atoms allocated at the perimeter in the nanoclusters scales approximately with the catalytic activity, suggesting that this fraction of most catalytically active Au sites changes with the size of the nanoclusters with an optimal size related to the $\mathrm{Au}$ loading of $5 \mathrm{~nm}$, as measured as the highest $\mathrm{NO}_{2}$ gas sensitivity for MWCNTs surface loaded with $5 \mathrm{~nm}$ of Au.

A typical $\mathrm{NO}_{2}$ gas detection at ppb level of interest for environmental monitoring is shown in Figure 4(b) by an MWCNT sensor loaded with $5 \mathrm{~nm}$ of $\mathrm{Au}$ at the operating temperature of $250^{\circ} \mathrm{C}$. A minimum detection of $200 \mathrm{ppb} \mathrm{NO}_{2}$ has been clearly measured. This threshold is considered as alarm level in the Italian regulations for air pollution. This very low detection level is attributed to a very high gas sensitivity of Au-modified gas sensors. In fact, our device operating at $250^{\circ} \mathrm{C}$ exhibits a gas response in terms of electrical change of $410 \Omega$ to $200 \mathrm{ppb} \mathrm{NO}_{2}$ that is comparable with the response of $450 \Omega$ to $100 \mathrm{ppb}$ $\mathrm{NO}_{2}$ of high-sensitive thermally treated CNTs chemiresistors operating at $165^{\circ} \mathrm{C}$ [4]. This detection limit of $200 \mathrm{ppb}$ $\mathrm{NO}_{2}$ is also comparable with the detection limit of $44 \mathrm{ppb}$
$\mathrm{NO}_{2}$ measured at room temperature by casting single-walled CNTs sensors reported in literature [5]. However, multiple single-walled carbon nanotube $n$-type devices functionalized with polyethyleneimine coating are capable of detecting $\mathrm{NO}_{2}$ at less than $1 \mathrm{ppb}$ concentration [7]. These very low levels of sub-ppb detection typically require high-resolution spectroscopy techniques. Finally, the detection limit of a few hundreds of $\mathrm{ppb}$ for our device could be further improved by an optimal choice of the Au clusters size and sensor working temperature.

Moreover, the baseline of the Au-loaded MWCNT sensor is found to drift due to the high mobility of $\mathrm{Au}$ atoms on CNTs sidewalls [25]. Generally, the mobility increases with the temperature, thus it was extremely difficult to obtain stable conditions of the baseline of the sensor at elevated temperatures. However, also the size of the Au-nanoclusters should be optimal to reduce the thermal drift effects on sensor baseline.

The cross-sensitivity of four MWCNT sensors, unmodified and Au-loaded, has been measured in terms of mean sensitivity $(\% / \mathrm{ppm})$, expressed as percentage relative resistance change $\Delta R / R_{i}(\%)$ weighted by exposed gas concentration (ppm) toward $\mathrm{NO}_{2}$ and $\mathrm{NH}_{3}$. Figure 5 reports the comparison of the chemical patterns obtained at working temperature of $200^{\circ} \mathrm{C}$. The experimental results indicate excellent selectivity of all MWCNT sensors to $\mathrm{NO}_{2}$ with respect to $\mathrm{NH}_{3}$ with an $\mathrm{NO}_{2}$ mean sensitivity higher up to more than an order of magnitude for MWCNTs loaded with $5 \mathrm{~nm}$ of Au. This property of the CNT sensors 


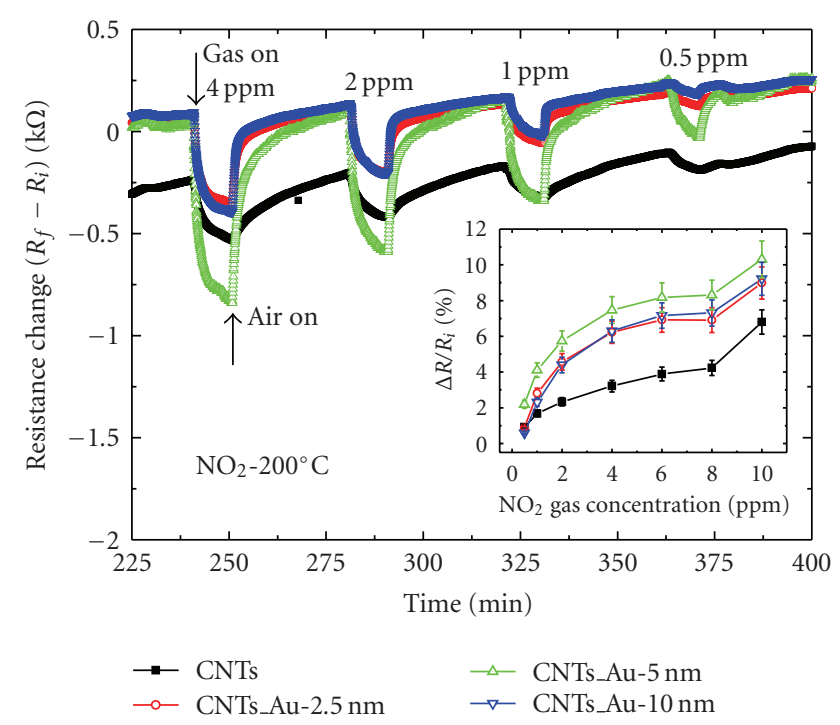

(a)

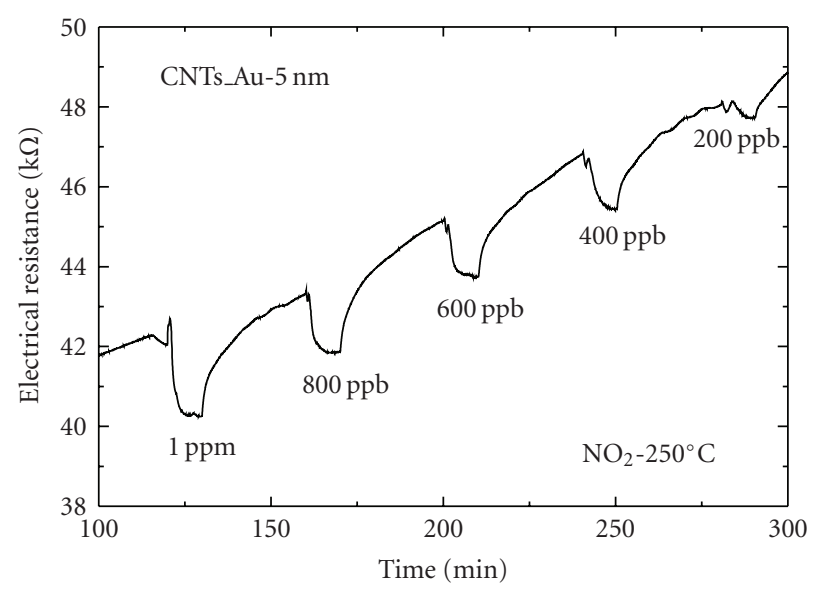

(b)

FIgURE 4: (a) Time response of the $\mathrm{NO}_{2}$ gas chemiresistor based on Co grown RF-PECVD MWCNT films, functionalized with Auloading of $2.5,5$, and $10 \mathrm{~nm}$, at working temperature of $200^{\circ} \mathrm{C}$. The MWCNTs thickness is about $250-300 \mathrm{~nm}$. The inset plots the calibration curves for four CNT sensors toward $\mathrm{NO}_{2}$ gas at $200^{\circ} \mathrm{C}$. (b) Time response of the $\mathrm{NO}_{2}$ gas chemiresistor based on Co grown RF-PECVD 250-300 nm-thick MWCNT films, functionalized with $\mathrm{Au}$-loading of $5 \mathrm{~nm}$ at working temperature of $250^{\circ} \mathrm{C}$.

based on surface functionalization with $\mathrm{Au}$ nanoclusters is very promising for environmental $\mathrm{NO}_{2}$ air-monitoring applications.

The effects of the temperature on the $\mathrm{NO}_{2}$ mean sensitivity of the MWCNTs, unloaded and Au-modified with 5 and $10 \mathrm{~nm}$, are reported in Figure 6. At a given operating temperature, the mean sensitivity of the Au-loaded MWCNT sensors results to be higher than unfunctionalized sensors; and the temperature of maximum $\mathrm{NO}_{2}$ sensitivity of the $\mathrm{Au}$ loaded MWCNT sensors decreases with Au-loading: sensor temperature of $200^{\circ} \mathrm{C}$ for MWCNT sensor loaded with $5 \mathrm{~nm}$ of $\mathrm{Au}$, and $150^{\circ} \mathrm{C}$ for MWCNT sensor loaded with $10 \mathrm{~nm}$ of Au. Probably, the catalytic activity of bigger Au

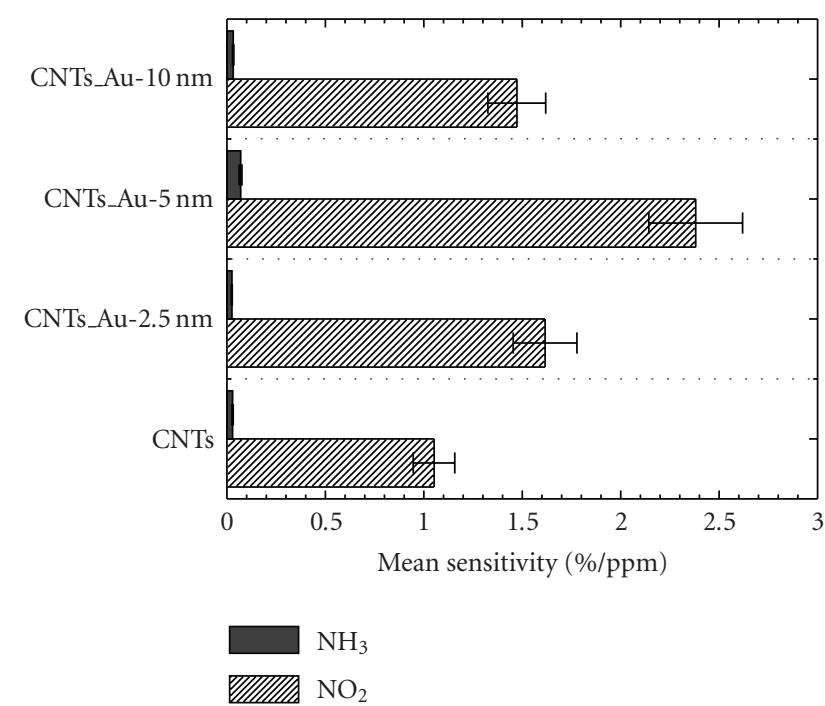

Figure 5: Comparison of mean sensitivity of the MWCNT chemiresistor, unmodified and Au-loaded of 2.5, 5, and $10 \mathrm{~nm}$, toward $\mathrm{NO}_{2}$ and $\mathrm{NH}_{3}$ gas at working temperature of $200^{\circ} \mathrm{C}$. The MWCNTs thickness is $250-300 \mathrm{~nm}$ and the nominal thickness of Co growth-catalyst is $6 \mathrm{~nm}$. The exposure time is 10 minutes.

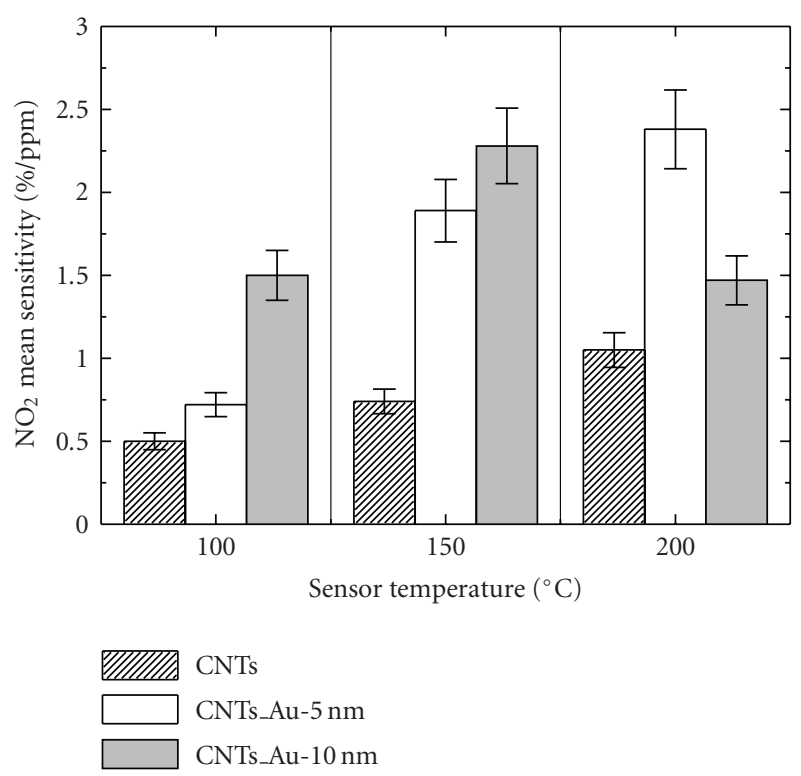

FIgURE 6: Comparison of $\mathrm{NO}_{2}$ mean sensitivity of the MWCNT chemiresistor, unmodified and Au-loaded of 5 and $10 \mathrm{~nm}$, as a function of sensor temperature in the range of $100-200^{\circ} \mathrm{C}$. The MWCNTs thickness is about $250-300 \mathrm{~nm}$ and the nominal thickness of Co growth-catalyst is $6 \mathrm{~nm}$. The exposure time is 10 minutes.

nanoclusters degrades with the increasing temperature in the range examined. In fact, the loss of low-coordinated Au atoms, present at the extended nanoclusters perimeter, is highly probable occurring upon thermal annealing at higher temperature considered resulting in a smoother and compact nanoclusters shape, as observed in Figure 3. 


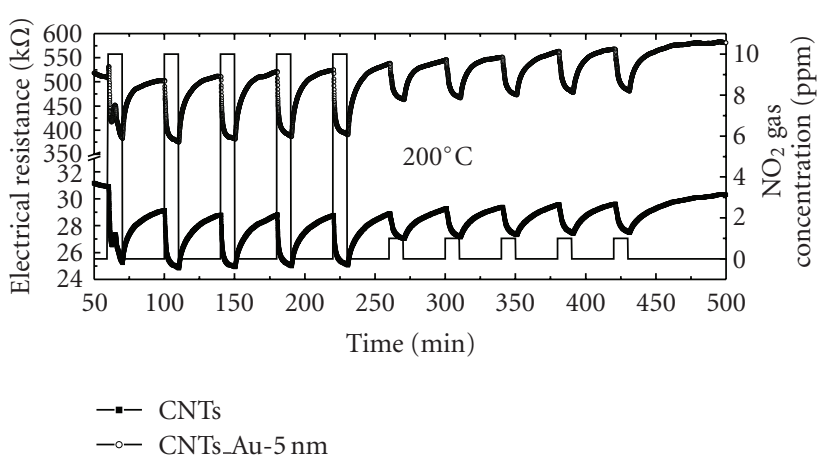

(a)

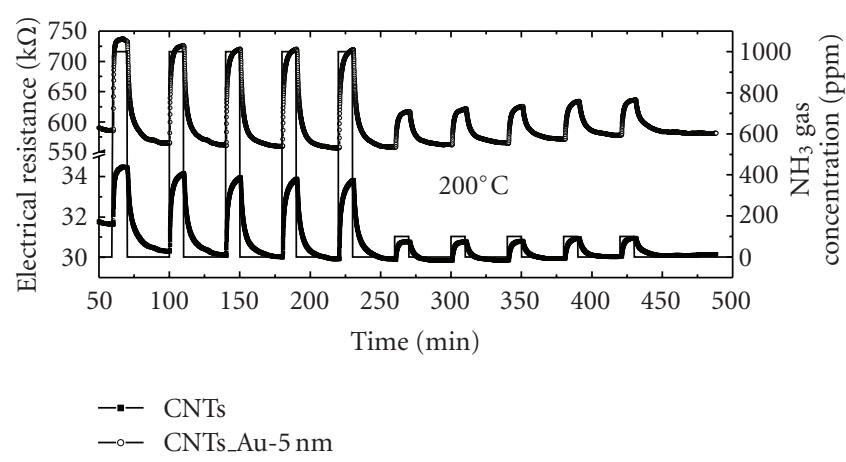

(b)

FIGURE 7: Repeatability of the response of the unfunctionalized and Au-5 nm modified MWCNT-based sensors toward 10-minute five pulses of (a) 10 and 1 ppm NO$~_{2}$ gas and (b) 1000 and $100 \mathrm{ppm} \mathrm{NH}_{3}$ gas at working temperature of $200^{\circ} \mathrm{C}$. The CNTs thickness is about $250-300 \mathrm{~nm}$ and the nominal thickness of the growth-catalyst of Co is $6 \mathrm{~nm}$.

TABle 1: Comparison of the coefficient of variation, $D$ (\%) for three MWCNT-based gas sensors: (i) CNTs unfunctionalized, (ii) CNTs modified with Au loading of $5 \mathrm{~nm}$, (iii) CNTs modified with Au loading of $10 \mathrm{~nm}$, toward five gas exposures of individual gas of 1 and $10 \mathrm{ppm} \mathrm{NO}, 100$ and $1000 \mathrm{ppm} \mathrm{NH}$. The sensor temperature for all sensors is $200^{\circ} \mathrm{C}$. The thickness of MWCNTs is about $250-300 \mathrm{~nm}$.

\begin{tabular}{|c|c|c|c|}
\hline \multirow{2}{*}{ Gas concentration } & \multicolumn{3}{|c|}{ Coefficient of variation, $D(\%)$} \\
\hline & Sensor CNTs & Sensor CNTs_Au-5 m & Sensor CNTs_Au-10 m \\
\hline $1 \mathrm{ppm} \mathrm{NO} 2$ & 3.4 & 3.1 & 2.9 \\
\hline 10 ppm $\mathrm{NO}_{2}$ & 14.1 & 1.2 & 3.0 \\
\hline $100 \mathrm{ppm} \mathrm{NH}_{3}$ & 5.1 & 2.9 & 3.5 \\
\hline $1000 \mathrm{ppm} \mathrm{NH}_{3}$ & 13.1 & 5.0 & 11.2 \\
\hline
\end{tabular}

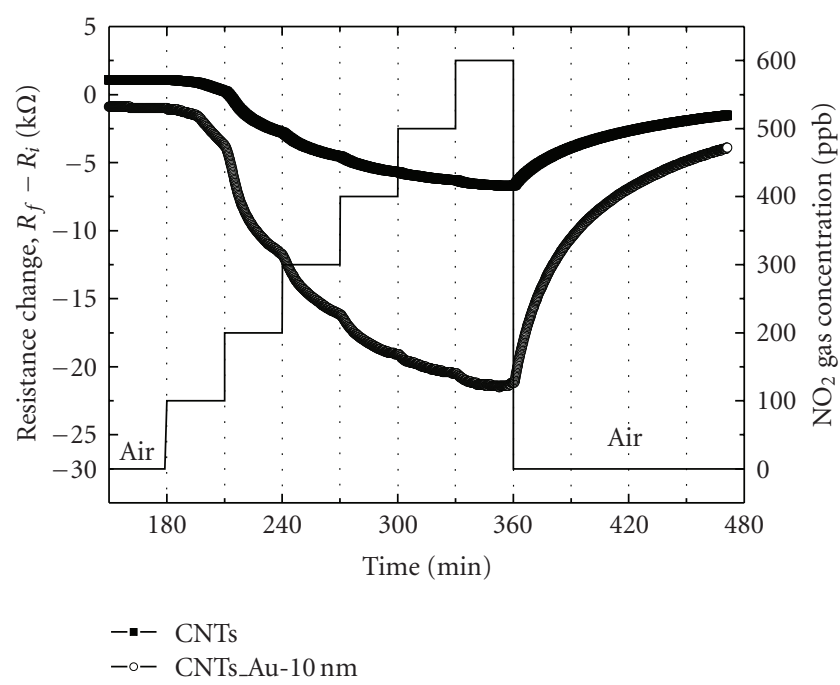

FIgURE 8: Time online responses of two chemiresistors based on unmodified CNTs and 10-nm loaded Au-modified CNTs (CNTs_Au-10 nm), exposed to 30-minute pulses of $\mathrm{NO}_{2}$ gas ranging from 100 to $600 \mathrm{ppb}$, at sensor temperature of $200^{\circ} \mathrm{C}$. The thickness of CNTs films is about $250-300 \mathrm{~nm}$.

Figure 7 reports the short-term repeatability of the response of the unfunctionalized and Au-modified MWCNTbased sensors, at working temperature of $200^{\circ} \mathrm{C}$ to 10 - minute five pulses of the individual gases of 10 and $1 \mathrm{ppm}$ $\mathrm{NO}_{2}$ and of 1000 and $100 \mathrm{ppm} \mathrm{NH}_{3}$. The experimental results indicate very good short-term repeatability in the real-time gas detection with better rate for the Au-modified MWCNT sensor. To evaluate the short-term repeatability of the gas response of the sensors, a figure of merit has been defined as the coefficient of variation, $D(\%)$, expressed by the percentage ratio of the standard deviation (SD) over mean $(M)$ for $n$ gas concentration exposures repeated. The coefficient of variation, $D$, is given by

$$
D(\%)=\frac{\mathrm{SD}}{M} \times 100 .
$$

The lower the coefficient of variation, $D$, the better is the short-term repeatability of the sensor to a given gas concentration repeated. The results achieved by calculating the coefficient of variation for three CNT-based sensors have been reported in Table 1. From data analysis, generally, the lowest $D$ has been measured for the CNT sensor modified with an Au-loading of $5 \mathrm{~nm}$, excluding the gas concentration of $1 \mathrm{ppm} \mathrm{NO}_{2}$. However, both Au-modified CNT sensors exhibit a coefficient of variation lower than that related to unfunctionalized CNT sensor; thus the Au-modified CNT sensors show a better short-term repeatability and the best repeatability has been found for the CNT sensor modified with an Au-loading of $5 \mathrm{~nm}$. These Au-modified CNT chemiresistors show a better short-term repeatability compared to the commercial TGS Taguchi gas sensors based 
on $\mathrm{SnO}_{2}$ thick films [26] used to detect volatile organic compounds (VOCs) in the range of gas concentration ranging from 25 to $100 \mathrm{ppm}$. In fact, the coefficient of variation, $D$, of our Au-modified CNT sensor results to be lower, up to about an order of magnitude, than that of the commercial TGS VOCs $\mathrm{SnO}_{2}$-sensors, reported in literature [26].

Figure 8 shows the continuous detection at sub-ppm level ranging from 100 to $600 \mathrm{ppb} \mathrm{NO}_{2}$ in the 30 minute step-pulse format using two CNT chemiresistors, at operating temperature of $200^{\circ} \mathrm{C}$. As observed, the CNT sensor functionalized with Au-10 nm loading is of higher sensitivity and higher resolution than unmodified CNT sensor, and the Au-modified CNT sensor is able to detect more efficiently also $100 \mathrm{ppb} \mathrm{NO}_{2}$ although being with a time-delayed response. This limit represents the $\mathrm{NO}_{2}$ attention level for environmental monitoring in the Italian regulations. Finally, the comparison shows that the continuous gas monitoring at ppb level of $\mathrm{NO}_{2}$ is effectively performed with Au-modified MWCNT chemiresistors.

\section{CONCLUSIONS}

In conclusion, CNT-based chemiresistors have been successfully fabricated onto low-cost alumina substrates using RF-PECVD technology for $\mathrm{NO}_{2}$ gas detection at operating temperature in the range of $100-250^{\circ} \mathrm{C}$. The surface modification of the CNT networked films with size-controlled $\mathrm{Au}$ nanoclusters enhances the $\mathrm{NO}_{2}$ gas sensitivity up to detection of sub-ppm level of great interest for selective environmental $\mathrm{NO}_{2}$ air monitoring. The effects of tailored Au-loading onto CNTs surface on $\mathrm{NO}_{2}$ gas sensitivity depend on nanoclusters size and sensor working temperature. An excellent short-term repeatability of the response to the selected targeted gases has been also measured for the Aumodified CNT-based sensors. A continuous gas monitoring at ppb level of $\mathrm{NO}_{2}$ has been effectively performed with CNT chemiresistors modified with a loading of Au-10 nm, at sensor temperature of $200^{\circ} \mathrm{C}$. The p-type character of the Au-modified CNT sensors has been also measured. Future work on different metal surface modifications of carbon nanotube networked films is planned for specific gas detection in sensor arrays concerning environmental monitoring applications.

\section{REFERENCES}

[1] S. Iijima, "Helical microtubules of graphitic carbon," Nature, vol. 354, no. 6348, pp. 56-58, 1991.

[2] M. S. Dresselhaus, G. Dresselhaus, and Ph. Avouris, Carbon Nanotubes: Synthesis, Structure, Properties, and Applications, Springer, Berlin, Germany, 2001.

[3] J. Kong, N. R. Franklin, C. Zhou, et al., "Nanotube molecular wires as chemical sensors," Science, vol. 287, no. 5453, pp. 622625, 2000.

[4] L. Valentini, I. Armentano, J. M. Kenny, C. Cantalini, L. Lozzi, and S. Santucci, "Sensors for sub-ppm $\mathrm{NO}_{2}$ gas detection based on carbon nanotube thin films," Applied Physics Letters, vol. 82, no. 6, pp. 961-963, 2003.
[5] J. Li, Y. Lu, Q. Ye, M. Cinke, J. Han, and M. Meyyappan, "Carbon nanotube sensors for gas and organic vapor detection," Nano Letters, vol. 3, no. 7, pp. 929-933, 2003.

[6] M. Penza, G. Cassano, R. Rossi, et al., "Effect of growth catalysts on gas sensitivity in carbon nanotube film based chemiresistive sensors," Applied Physics Letters, vol. 90, no. 10, Article ID 103101, 3 pages, 2007.

[7] P. Qi, O. Vermesh, M. Grecu, et al., "Toward large arrays of multiplex functionalized carbon nanotube sensors for highly sensitive and selective molecular detection," Nano Letters, vol. 3, no. 3, pp. 347-351, 2003.

[8] J. Zhang, A. Boyd, A. Tselev, M. Paranjape, and P. Barbara, "Mechanism of $\mathrm{NO}_{2}$ detection in carbon nanotube field effect transistor chemical sensors," Applied Physics Letters, vol. 88, no. 12, Article ID 123112, 3 pages, 2006.

[9] A. Cusano, M. Consales, A. Cutolo, et al., "Optical probes based on optical fibers and single-walled carbon nanotubes for hydrogen detection at cryogenic temperatures," Applied Physics Letters, vol. 89, no. 20, Article ID 201106, 3 pages, 2006.

[10] M. Penza, G. Cassano, P. Aversa, et al., "Alcohol detection using carbon nanotubes acoustic and optical sensors," Applied Physics Letters, vol. 85, no. 12, pp. 2379-2381, 2004.

[11] B. Mahar, C. Laslau, R. Yip, and Y. Sun, "Development of carbon nanotube-based sensors-a review," IEEE Sensors Journal, vol. 7, no. 2, pp. 266-284, 2007.

[12] J. P. Novak, E. S. Snow, E. J. Houser, D. Park, J. L. Stepnowski, and R. A. McGill, "Nerve agent detection using networks of single-walled carbon nanotubes," Applied Physics Letters, vol. 83, no. 19, pp. 4026-4028, 2003.

[13] A. Modi, N. Koratkar, E. Lass, B. Wei, and P. M. Ajayan, "Miniaturized gas ionization sensors using carbon nanotubes," Nature, vol. 424, no. 6945, pp. 171-174, 2003.

[14] S. Kim, H. R. Lee, Y. J. Yun, et al., "Effects of polymer coating on the adsorption of gas molecules on carbon nanotube networks," Applied Physics Letters, vol. 91, no. 9, Article ID 093126, 3 pages, 2007.

[15] M. Penza, M. A. Tagliente, P. Aversa, M. Re, and G. Cassano, "The effect of purification of single-walled carbon nanotube bundles on the alcohol sensitivity of nanocomposite Langmuir-Blodgett films for SAW sensing applications," Nanotechnology, vol. 18, no. 18, Article ID 185502, 12 pages, 2007.

[16] L. Valentini, V. Bavastrello, E. Stura, I. Armentano, C. Nicolini, and J. M. Kenny, "Sensors for inorganic vapor detection based on carbon nanotubes and poly (o-anisidine) nanocomposite material," Chemical Physics Letters, vol. 383, no. 5-6, pp. 617622, 2004.

[17] E. Bekyarova, M. Davis, T. Burch, et al., "Chemically functionalized single-walled carbon nanotubes as ammonia sensors," Journal of Physical Chemistry B, vol. 108, no. 51, pp. 1971719720, 2004.

[18] J. Kong, M. G. Chapline, and H. Dai, "Functionalized carbon nanotubes for molecular hydrogen sensors," Advanced Materials, vol. 13, no. 18, pp. 1384-1386, 2001.

[19] M. Penza, G. Cassano, R. Rossi, et al., "Enhancement of sensitivity in gas chemiresistors based on carbon nanotube surface functionalized with noble metal $(\mathrm{Au}, \mathrm{Pt})$ nanoclusters," Applied Physics Letters, vol. 90, no. 17, Article ID 173123, 2007.

[20] S. Peng, K. Cho, P. Qi, and H. Dai, "Ab initio study of CNT $\mathrm{NO}_{2}$ gas sensor," Chemical Physics Letters, vol. 387, no. 4-6, pp. 271-276, 2004.

[21] N. H. Quang, M. Van Trinh, B.-H. Lee, and J.-S. Huh, "Effect of $\mathrm{NH}_{3}$ gas on the electrical properties of single-walled carbon 
nanotube bundles," Sensors and Actuators B, vol. 113, no. 1, pp. 341-346, 2006.

[22] R. J. Chen, N. R. Franklin, J. Kong, et al., "Molecular photodesorption from single-walled carbon nanotubes," Applied Physics Letters, vol. 79, no. 14, pp. 2258-2260, 2001.

[23] B. Hvolbæk, T. V. W. Janssens, B. S. Clausen, H. Falsig, C. H. Christensen, and J. K. Nørskov, "Catalytic activity of Au nanoparticles," Nano Today, vol. 2, no. 4, pp. 14-18, 2007.

[24] T. Nowitzki, P. Nickut, C. Deiter, J. Wollschläger, K. AlShamery, and M. Bäumer, "Au deposits on graphite: on the nature of high temperature desorption peaks in CO thermal desorption spectra," Surface Science, vol. 600, no. 18, pp. 35953599, 2006.

[25] Y. Zhang, N. W. Franklin, R. J. Chen, and H. Dai, "Metal coating on suspended carbon nanotubes and its implication to metal-tube interaction," Chemical Physics Letters, vol. 331, no. 1, pp. 35-41, 2000.

[26] E. Llobet, J. Brezmes, X. Vilanova, J. E. Sueiras, and X. Correig, "Qualitative and quantitative analysis of volatile organic compounds using transient and steady-state responses of a thick-film tin oxide gas sensor array," Sensors and Actuators B, vol. 41, no. 1-3, pp. 13-21, 1997. 

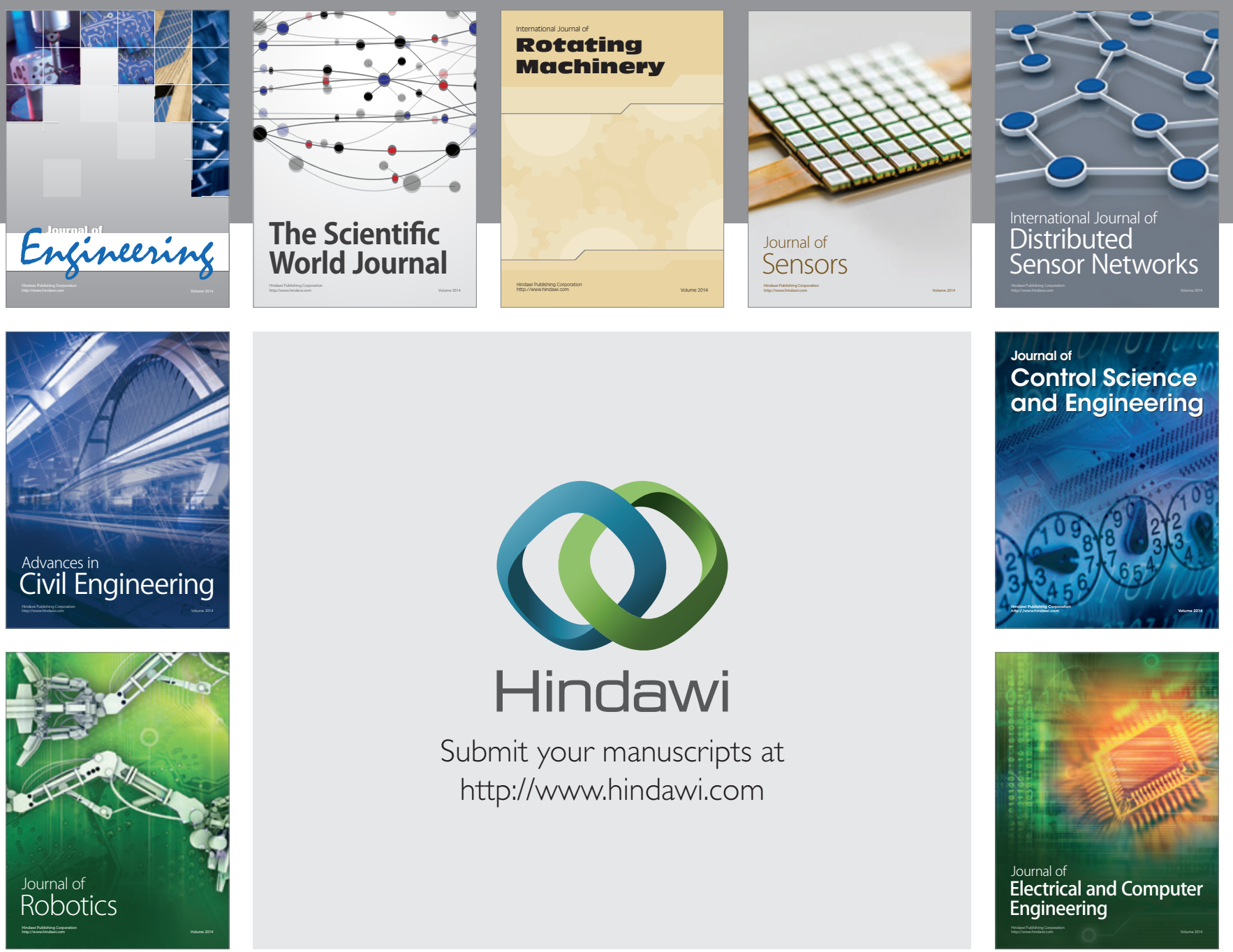

Submit your manuscripts at

http://www.hindawi.com
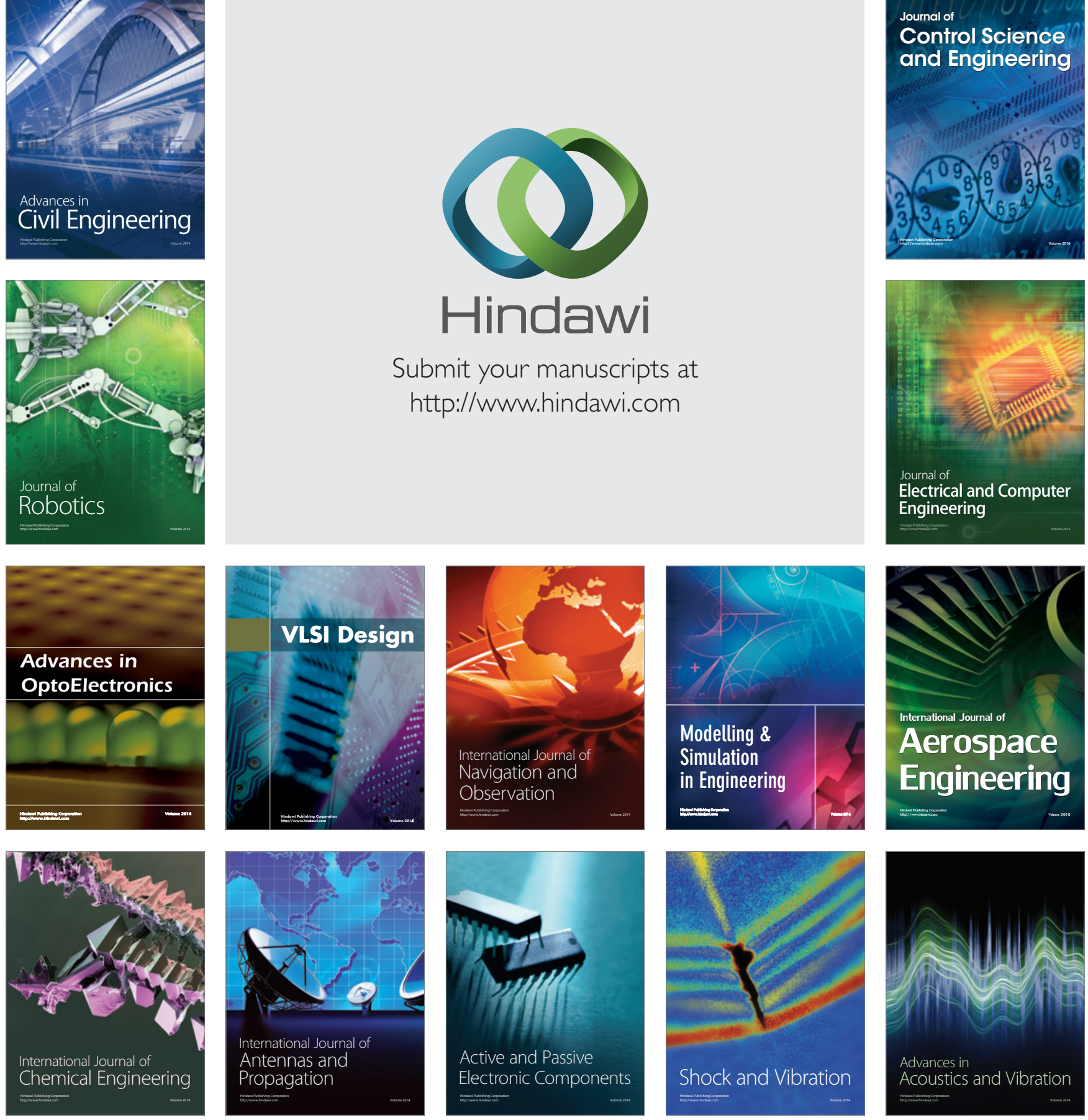